\section{El Aprendizaje-Servicio en educación superior. Teoría, práctica y perspectiva crítica}

\section{Reseña}

\section{Laura Lucchetti Guarch}

El libro "El Aprendizaje-Servicio en educación superior. Teoría, práctica y perspectiva crítica" de Susan J. Deeley (2016, Narcea) surge de la necesidad de la autora de profundizar en el funcionamiento de esta metodología en relación a la educación superior. J.Deeley nos ofrece un análisis teórico profundo sobre este tipo de aprendizaje complementándolo con evidencias empíricas fruto de sus investigaciones educativas. El lector puede realizar una lectura global o, si lo desea, centrar su atención en algunos de los capítulos pensados para leerlos separadamente.

La obra organizada en ocho capítulos, proporciona tanto un marco conceptual sobre el aprendizaje servicio como algunas aportaciones prácticas. En la primera parte la autora presenta la metodología, la contextualiza, la define y hace una primera aproximación a los resultados que se pueden obtener mediante este tipo de proyectos. Una vez hecha esta introducción se centra en cómo se alcanza el aprendizaje en estas prácticas con la voluntad de aportar un modelo teórico que las sustente. De este modo hace un recorrido analítico por distintas teorías del aprendizaje tales como la relación entre pensamiento y lenguaje en relación a las aportaciones de Dewey y
Vygotsky, el constructivismo social, el aprendizaje colaborativo y el aprendizaje experiencial, entre otras. Seguidamente amplia el contenido anterior presentando y defendiendo el aprendizaje servicio como una pedagogía crítica, entendiendo que su objetivo es el de favorecer el desarrollo de personas críticas que pueden generar acciones de cambio social.

En este marco la reflexión crítica se presenta como elemento fundamental en el proceso de concienciación y como dinamismo pedagógico clave en los proyectos de aprendizaje servicio. Esta permite el desarrollo personal e intelectual del alumnado, a la vez que dota de sentido el aprendizaje y las acciones de servicio, vinculando estos dos elementos. La autora dedica un capítulo a su conceptualización y análisis en profundidad, para posteriormente abordar la concreción de la reflexión crítica mediante la escritura académica en los proyectos de aprendizaje servicio. En esta parte de carácter más práctico se nos explican dos estrategias que hacen posible el desarrollo de la reflexión crítica: la redacción de incidentes críticos y los diarios reflexivos. Complementando el contenido teórico que aporta encontramos ejemplos reales del uso de estas dos herramientas, que ilustran y permiten entender su funcionamiento. Por último, se destina un capítulo a las reflexiones del alumnado durante la evaluación de los proyectos.

Para finalizar Deeley presenta sus conclusiones y reflexiones finales, recuperando los objetivos marcados al inicio del texto, aportando una reflexión 
de carácter personal y remarcando la necesidad de seguir investigando para desarrollar y mejorar las prácticas de aprendizaje servicio en educación superior. perspectiva crítica. RIDAS, Revista Iberoamericana de Aprendizaje Servicio, 3, 164-165. 